\title{
Simultaneous Occurrence of Three Different Valence Tautomers in meso-Vinylruthenium-Modified Zinc Porphyrin Radical Cations
}

\author{
Jing Chen, ${ }^{\dagger}$ Evelyn Wuttke, ${ }^{\dagger}$ Walther Polit, ${ }^{\dagger}$ Thomas Exner, ${ }^{*}$ and Rainer F. Winter*, ${ }^{*}$ \\ ${ }^{\dagger}$ Fachbereich Chemie, Universität Konstanz, Universitätsstraße 10, D-78457 Konstanz, Germany \\ ${ }^{\star}$ Pharmazeutisches Institut, Eberhard-Karls Universität Tübingen, Auf der Morgenstelle 8, D-72076 Tübingen, Germany
}

Supporting Information

\begin{abstract}
The mixed-valent radical cation of a styrylruthenium-modified meso-tetraarylzinc porphyrin forms a mixture of three different valence tautomers (VTs) in $\mathrm{CH}_{2} \mathrm{Cl}_{2}$ or $1,2-\mathrm{C}_{2} \mathrm{H}_{4} \mathrm{Cl}_{2}$ solutions. One of these VTs has the charge and spin delocalized over the porphyrin and the styrylruthenium moieties, while the other two display charge and spin localization on just one of the different redox sites. The relative amounts of the three different VTs were determined by EPR and IR spectroscopies at variable temperatures, while delocalization in the ground state was confirmed by DFT calculations.
\end{abstract}

$\mathrm{V}$ alence tautomers (VTs) are isomers that differ with respect to the electron distribution and redox-state assignment between two different redox-active entities of the same molecule. ${ }^{1,2}$ They constitute bistable systems whose optical or magnetic properties can be controlled by exterior physical stimuli such as temperature, pressure, light, applied magnetic field, or changes in their environment. ${ }^{2,3}$ This makes them promising candidates for switchable materials with possible use in information storage. The vast majority of VT systems derive from the combination of a redox-active metal ion and a redox-active, "non-innocent" ligand, 4,5 which are oxidized or reduced at similar potentials. A particularly rich chemistry has evolved around the family of catecholate, semiquinonate, and quinone redox systems, where many of the conceivable permutations arising from the isoelectric replacement of oxolate $\left(\mathrm{RO}^{-}\right)$by thiolate $\left(\mathrm{RS}^{-}\right)$or amide $\left(\mathrm{R}_{2} \mathrm{~N}^{-}\right)$donors have been realized. ${ }^{1 \mathrm{~b}, 6-9}$ Other examples are transition metal complexes of porphyrins, some with relevance to the active sites of metalloenzymes. ${ }^{10}$ Less common are VTs that are based on mixed-valent (MV) systems with nonidentical redox sites of similar intrinsic redox potentials. Here, the necessary condition of a double minimum ground-state hypersurface with a small free-energy gap $\Delta G_{0}$ between the individual minima and an energy barrier of sufficient height to allow for the coexistence of two isomeric forms requires a delicate balance of the electronic coupling parameter $H_{\mathrm{AB}}$ and the free-energy difference $\Delta G_{0}$, which is only rarely achieved. ${ }^{11}$ Increasing $H_{\mathrm{AB}}$ aids in delocalizing the charge over the available redox sites while at the same time diminishing the energy gap between the VTs from its thermodynamic value $\Delta G_{0}$ in the diabatic case $\left(H_{\mathrm{AB}}=0\right)$ to $\Delta G_{1}$ (Figure 1$) .{ }^{11}$ The few reported examples include pyrazine-bridged triruthenium clusters with

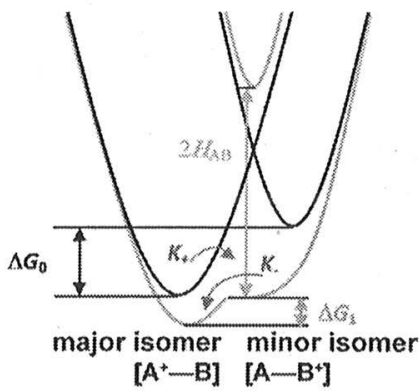

Figure 1. Potential hypersurface for an asymmetric MV system with unequal redox sites of similar redox potentials.

either two slightly different triruthenium subunits or an asymmetric bridge, ${ }^{11,12}$ a ferrocenylvinyl-tris(chlorophenyl). methyl radical, ${ }^{13}$ ferrocenyl- or triarylamine-substituted diprotonated anthraquinones or pyrylium salts, ${ }^{14}$ and biferrocenylbridged bis(ethynyl)diiron, iron/ruthenium, and iron/osmium complexes. ${ }^{15}$

Vinyl-substituted ruthenium complexes constitute redoxactive metal-organic $\pi$-systems whose HOMO receives major contributions from the alkenyl ligand. ${ }^{16}$ Oxidized styrylruthenium complexes featuring another conjugated organic or metal-organic redox-system with similar redox potential usually adopt a delocalized electronic structure. ${ }^{17}$ We now observed that the one-electron-oxidized meso-tetraarylzinc porphyrin styrylruthenium conjugates 1 and 2 of Chart 1 form an equilibrated mixture of three VTs where the positive charge is either localized on the zinc porphyrin ( $\mathrm{Zn}$-TPP ${ }^{\circ+}$. StyRu) or the styrylruthenium site (Zn-TPP-StyRu ${ }^{\circ+}$ ) or delocalized over both $\left([\mathbf{Z n} \text {-TPP-StyRu }]^{\circ+}\right)(\mathrm{Zn}-\mathrm{TPP}=$ 5,10,15-tris(3,5-di'butylphenyl) zinc porphyrin, StyRu $=$ $-\mathrm{C}_{6} \mathrm{H}_{4}-\mathrm{CH}=\mathrm{CH}-\mathrm{Ru}(\mathrm{X})(\mathrm{CO})\left(\mathrm{P}^{i} \mathrm{Pr}_{3}\right)_{2}(\mathrm{X}=\mathrm{Cl}$ or OOCC $\left._{6} \mathrm{H}_{4} \mathrm{CN}-4-\kappa^{2} \mathrm{O}\right)$.

The monoethynylated zinc tetraphenylporphyrin (Zn-TPP, L) was synthesized according to known literature procedures. ${ }^{18}$ Complex 1 was obtained in $65 \%$ yield by the regio- and stereoselective insertion of the ethynyl function of $\mathbf{L}$ into the metal-hydride bond of $\mathrm{RuClH}(\mathrm{CO})\left(\mathrm{P}^{i} \mathrm{Pr}_{3}\right)_{2}$. NMR spectroscopy shows the presence of a trans-disubstituted vinyl group as well as the signals of six equivalent ${ }^{i} \operatorname{Pr}$ groups in a 1:1 integral ratio with the signals of the $\mathrm{Zn}$-TPP, the characteristic ${ }^{13} \mathrm{C}$ 
Chart 1. Structures of $\mathrm{Zn}$-TPP (L) and VinylrutheniumModified Zn-TPP Complexes 1 and 2

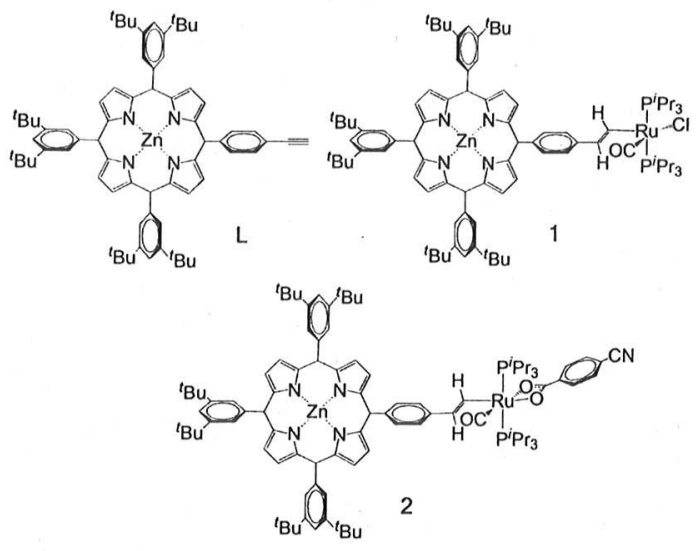

signals of the vinyl group and the $\mathrm{Ru}(\mathrm{CO})$ ligand, and a sharp singlet in the ${ }^{31} \mathrm{P}$ NMR spectrum (see the Supporting Information (SI)). Treatment of complex 1 with 1 equiv of sodium 4-cyanobenzoate produced complex 2 in a yield of $85 \%$ (see SI).

In the $\mathrm{NBu}_{4} \mathrm{PF}_{6} / \mathrm{CH}_{2} \mathrm{Cl}_{2}(0.1 \mathrm{M})$ electrolyte, $\mathrm{L}$ undergoes two reversible one-electron oxidations at half-wave potentials of 0.351 and $0.678 \mathrm{~V}$ and one reversible reduction at $-1.866 \mathrm{~V}$ (Figure 2a). Considering the innocent character of the $\mathrm{Zn}^{2+}$

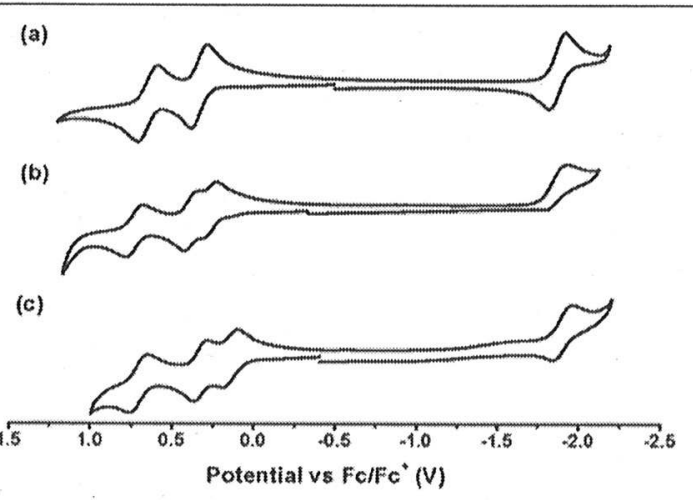

Figure 2. Cyclic voltammograms $\left(\mathrm{CH}_{2} \mathrm{Cl}_{2}, 0.1 \mathrm{M} \mathrm{NBu}_{4} \mathrm{PF}_{6}, \mathrm{rt}\right)$ of $\mathrm{Zn}$ TPP L (a) and of complexes 1 (b) and 2 (c).

cation, all redox processes involve the porphyrin $\pi$-system. Under the same conditions, complexes 1 and 2 show one additional redox couple close to the first oxidation of the zinc porphyrin, which is obviously due to the styrylruthenium moiety (Figure 2b,c). Redox potentials are 0.248, 0.374, 0.740, and $-1.966 \mathrm{~V}$ (peak potential of irreversible process) for $\mathbf{1}$ and $0.145,0.329,0.714$, and $-1.897 \mathrm{~V}$ for 2 . Considering the potentials of the first anodic process of $\mathrm{L}$ and those of the styrylruthenium complexes $\mathrm{RuCl}(\mathrm{CH}=\mathrm{CHPh})(\mathrm{CO})\left(\mathrm{P}^{\mathrm{i}} \mathrm{Pr}_{3}\right)_{2}$ $\left(\mathrm{Ru}_{\mathrm{ST}}, 0.270 \mathrm{~V}\right)$ and $\mathrm{Ru}(\mathrm{CH}=\mathrm{CHPh})\left(\mathrm{OOCC}_{6} \mathrm{H}_{4} \mathrm{CN}-4-\kappa^{2} \mathrm{O}\right)$ (CO) $\left(\mathrm{P}^{i} \operatorname{Pr}_{3}\right)_{2}(0.182 \mathrm{~V}$; SI Figure 3), the intrinsic energy gap between the two VTs is estimated as -0.081 and $-0.169 \mathrm{~V}$, corresponding to -7.8 or $-16.3 \mathrm{~kJ} / \mathrm{mol}$ in favor of the $\mathrm{Zn}$ TPP-StyRu ${ }^{\circ+}$ form.

The radical cations $\mathrm{L}^{\bullet+}, \mathbf{1}^{\circ+}$, and $2^{\circ+}$ were generated from their neutral precursors by oxidation with the $\mathrm{SbF}_{6}{ }^{-}$salt of the acetylferrocenium ion as a stoichiometric one-electron oxidant.
$\mathrm{L}^{\bullet+}$ displays a sharp isotropic EPR signal at $g=1.999$ in fluid $\mathrm{CH}_{2} \mathrm{Cl}_{2}$ solution or at $\mathrm{g}=2.000$ in frozen solutions or as a solid (SI Figure 4), which is characteristic of porphyrin-based radical cations. ${ }^{19} \mathrm{No}{ }^{14} \mathrm{~N}$ or ${ }^{1} \mathrm{H}$ hyperfine splittings were resolved. The same kind of signal $(g=2.002)$ was also observed for solid $1^{\bullet+}$, classifying it as an entirely $\mathrm{Zn}$-TPP centered paramagnetic species under these conditions (see SI Figure 5).

The situation changes dramatically, however, in $\mathrm{CH}_{2} \mathrm{Cl}_{2}$ or $1,2-\mathrm{C}_{2} \mathrm{H}_{4} \mathrm{Cl}_{2}$ solution, where separate signals coexist in a $T$. dependent equilibrium (Figure 3 ). The sharp isotropic signal at

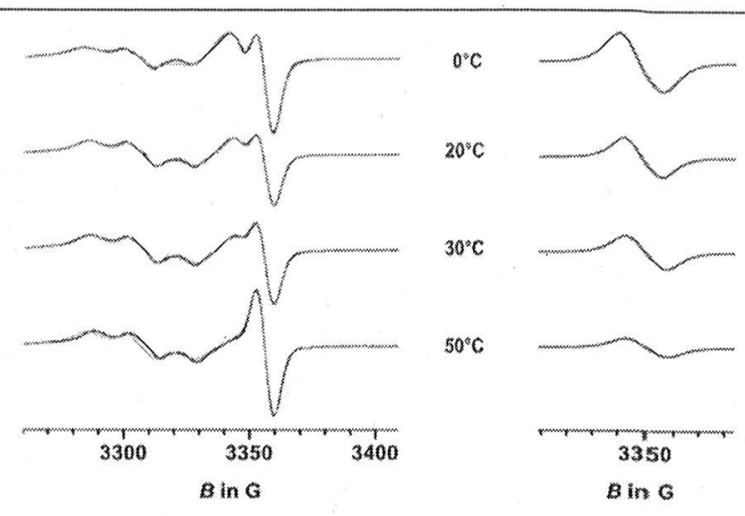

Figure 3. EPR spectra of radical cation $\mathbf{1}^{\circ+}$ in $1,2-\mathrm{C}_{2} \mathrm{H}_{4} \mathrm{Cl}_{2}$ at various temperatures. Left: overlay of experimental (black lines) and simulated spectra (red lines). Right: subspectrum of the [Zn-TPP-StyRu ${ }^{\bullet+}$ VT after subtraction of the contributions of the other VTs.

$g=2.001$ is readily assigned as belonging to the $\mathbf{Z n}$-TPP ${ }^{\circ+}$. StyRu VT. The second signal, a resolved triplet at $g=2.029$ with $A\left({ }^{31} \mathrm{P}\right)=15.6 \mathrm{G}$, shows the typical signature of a styrylruthenium-type radical cation, indicating that the second species is the $\mathbf{Z n}$-TPP-StyRu ${ }^{\circ+}$ isomer. As $T$ is lowered, the relative intensity of the triplet signal increases with respect to the singlet for $\mathrm{Zn}$-TPP ${ }^{\circ+}$-StyRu.

In keeping with findings on other oxidized aryl-substituted vinylruthenium complexes, ${ }^{16}$ the triplet signal of $\mathrm{Zn}$-TPP$\mathrm{StyRu}^{\circ+}$ collapses into a broad isotropic signal with no resolved hyperfine splitting on cooling below $-40^{\circ} \mathrm{C}$ or on freezing. Spectral changes with temperature are fully reversible as long as the temperature is maintained below $50{ }^{\circ} \mathrm{C}$, where the sample gradually decomposes. While the radical cation of benzoate complex 2 behaves in an overall similar manner to $1^{\circ+}$, there are three differences: (i) at comparable temperature, the contribution of the $\mathrm{Zn}$-TPP-StyRu ${ }^{\circ+}$ VT is predictably higher than for $1^{\circ+}$ (cf. the lowering of the half-wave potential of the StyRu-based redox couple as the 16 valence electron (VE) count in 1 changes to $18 \mathrm{VE}$ in 2); (ii) even at higher $T$ in solution, the signal of the $\mathrm{Zn}$-TPP-StyRu ${ }^{\circ+}$ VT does not exhibit resolved hyperfine splitting; and (iii) signals of both VTs are already present in solid samples of $2^{\circ+}$ (SI Figures 6 and 7).

The equilibrium indicated by EPR spectroscopy also leaves its marks in IR spectroscopy. Spectra of radical cations $1^{\circ+}$ and $2^{\circ+}$ in $\mathrm{CH}_{2} \mathrm{Cl}_{2}$ or $\mathrm{CH}_{2} \mathrm{Cl}_{2} / \mathrm{NBu}_{4} \mathrm{PF}_{6}$ display two separate $\mathrm{Ru}(\mathrm{CO})$ bands located at 1918 and $1964 \mathrm{~cm}^{-1}$ for $1^{\circ+}$ or at 1912 and $1969 \mathrm{~cm}^{-1}$ for $2^{\circ+}$ (Figure 4a and SI Figure 8). The band at the lower energy is only slightly blue-shifted with respect to that in the neutral complexes $1(\tilde{\nu}(\mathrm{CO})=1912$ $\left.\mathrm{cm}^{-1}\right)$ and $2\left(\tilde{\nu}(\mathrm{CO})=1906 \mathrm{~cm}^{-1}\right)$ and is in the regime expected of a vinylruthenium complex undergoing electron transfer from an appended oxidizable unit with little 

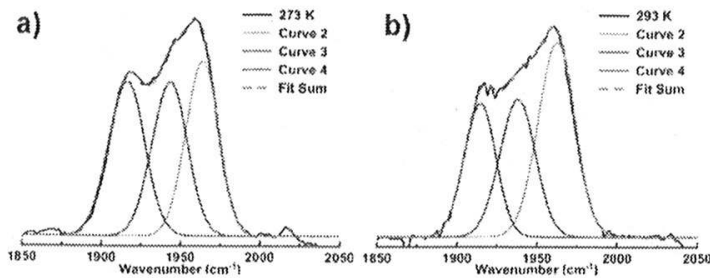

c)

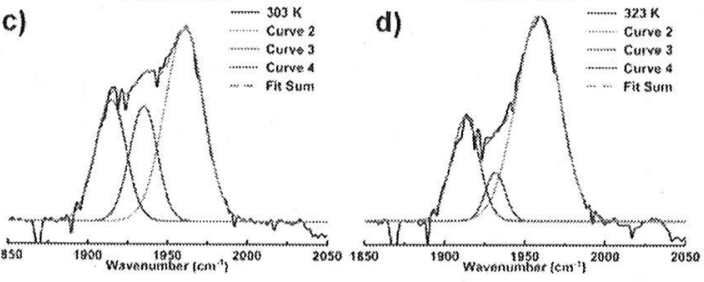

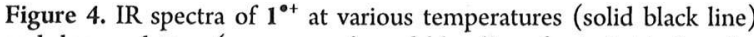
and deconvolution (green, purple and blue lines for individual peaks, red line for their sum).

conjugation to the $\{\mathrm{Ru}(\mathrm{CH}=\mathrm{CHR})(\mathrm{CO})\}$ moiety. ${ }^{20}$ It is thus assigned to the $\mathrm{Zn}-\mathrm{TPP}^{\mathbf{0}}$-StyRu VT. The band at the higher energy falls close to that of other donor-substituted styrylruthenium radical cations such as $[\mathrm{RuCl}(\mathrm{CH}=$ $\left.\left.\mathrm{CHC}_{6} \mathrm{H}_{4}-\mathrm{OMe}-4\right)(\mathrm{CO})\left(\mathrm{P}^{i} \mathrm{Pr}_{3}\right)_{2}\right]^{\bullet+}\left(\tilde{\nu}(\mathrm{CO})=1966 \mathrm{~cm}^{-1}\right)$ and hence is ascribed to $\mathrm{Zn}$-TPP-StyRu ${ }^{\circ+}$. For comparison, the $\mathrm{Ru}(\mathrm{CO})$ band of both oxidized $\mathrm{RuCl}(\mathrm{CH}=\mathrm{CHPh})(\mathrm{CO})$. $\left(\mathrm{P}^{i} \mathrm{Pr}_{3}\right)_{2}$ and $\left[\mathrm{Ru}(\mathrm{CH}=\mathrm{CHPh})-\left(\mathrm{OOCC}_{6} \mathrm{H}_{4} \mathrm{CN}-4-\mathrm{K}^{2} \mathrm{O}\right)(\mathrm{CO})\right.$ $\left.\left(\mathrm{P}^{i} \mathrm{Pr}_{3}\right)_{2}\right]^{0+}$ appears at $1976 \mathrm{~cm}^{-1}$ (SI Figure 10). Further oxidation to the dications induces only a minor additional blue shift of the $\mathrm{Ru}(\mathrm{CO})$ band of the $\mathrm{Zn}$-TPP-StyRu ${ }^{\circ+}$ form to $1972 \mathrm{~cm}^{-1}$ for $\mathbf{1}^{2+}$ and $2^{2+}$ (SI Figure 8 and Table 1 for a more comprehensive list of vibrations). In further agreement with the EPR data, the relative proportions of the $\mathrm{Zn}$-TPP-StyRu ${ }^{\circ+}$ isomer are larger for $\mathbf{2}^{\circ+}$ (SI Figure 8). While solid samples of radical cations $1^{\circ+}$ and $2^{\circ+}$ exhibit an IR band at 1267 and 1276 $\mathrm{cm}^{-1}$, respectively, the intensity of this band is notably lower for $2^{\circ+}$ (SI Figures 11 and 12). Such a band has been established as diagnostic of a porphyrin-based radical cation. ${ }^{21}$

A closer look at the solution EPR spectra of $1^{\circ+}$ recorded between -110 to $+50{ }^{\circ} \mathrm{C}$ reveals the presence of a third signal at a $g$ value close to that of the $\mathbf{Z n}$-TPP ${ }^{\circ+}$-StyRu VT (Figure 3 and SI Figure 14). The only slight displacement from $g_{\mathrm{e}}$ and the broadening of the signal point to a dominant organic character of the underlying species and an increased metal contribution to the SOMO with respect to $\mathrm{Zn}$-TPP ${ }^{\circ+}$-StyRu. Spectral deconvolution clearly indicates the presence of a third $\mathrm{Ru}(\mathrm{CO})$ band at 1932 or $1946 \mathrm{~cm}^{-1}$ for solutions of $1^{\circ+}$ or $2^{\circ+}$, respectively, in the region between the two resolved $\mathrm{Ru}(\mathrm{CO})$ bands assigned to $\mathbf{Z n}$-TPP-StyRu ${ }^{\circ+}$ and $\mathbf{Z n}$-TPP ${ }^{\circ+}$-StyRu (see Figure $4 b-d$ ). We also observe extremely broad electronic bands in the near-infrared (NIR) that protrude well into the mid-IR with peaks at ca. 6000 and $4900 \mathrm{~cm}^{-1}$ for $1^{\circ+}$ or 5850 and $4150 \mathrm{~cm}^{-1}$ for $2^{\circ+}$ that are absent in the spectra of solid $1^{\bullet+}$, i.e., under conditions where only the $\mathrm{Zn}$-TPP $^{\circ+}{ }_{-}$StyRu form is present (SI Figure 13). $\mathrm{Ru}(\mathrm{CO})$ bands of such energy and low-energy electronic transitions of that kind are typical of paramagnetic, MV styrylruthenium complexes where the charge is delocalized onto a secondary redox-active, $\pi$-conjugated entity such as $[\text { StyRu-NAn }]^{\circ+}\left(\mathrm{An}=\right.$ anisyl, $\left.\mathrm{C}_{6} \mathrm{H}_{4} \mathrm{OMe}-4\right){ }^{17 \mathrm{~b}}$ We therefore assign this third species as the [Zn-TPP-StyRu $]^{\circ+}$
VT with the unpaired spin and the positive charge (hole) shared between the $\mathrm{Zn}$-TPP and the StyRu moieties.

The $T$-dependent equilibrium between the three VTs of $1^{\circ+}$ was investigated by full digital simulation of the EPR spectra utilizing the EPR parameters extracted for $\mathbf{L}^{\bullet+}$ and $\mathbf{R u}_{\mathrm{ST}}{ }^{\circ+}$ (Figure 3 and SI Figures 14 and 15) as the initial input parameters. Difference spectra obtained by subtracting appropriately weighed subspectra of the $\mathbf{Z n}-\mathrm{TPP}^{\circ+}{ }_{-} \mathbf{S} \mathbf{t y R} \mathbf{u}$ and the Zn-TPP-StyRu ${ }^{\circ+}$ VTs with optimized $A\left({ }^{31} \mathrm{P}\right), A\left({ }^{99 / 101} \mathrm{Ru}\right)$, and $g$-values result in a broadened isotropic peak at $g=2.007$ for $[\mathrm{Zn} \text {-TPP-StyRu }]^{\bullet+}$. Figure 3 and SI Figure 14 show that the added subspectra fit the experimental ones very well (for simulation parameters see the SI). Relative amounts of the three species as calculated from the integration of the appropriately weighed subspectra reveal that the relative proportion of the delocalized VT increases at the expense of those of the two more localized ones as $T$ is lowered (SI Table 3 ). The same trend is observed from $T$-dependent solution IR spectra at selected temperatures (see Figure 4 and SI Figures 16 and 17 and Table 4). We point out that the integrals for the deconvoluted IR bands do not necessarily match the relative concentrations as the oscillator strengths of the individual species may differ from each other. Direct comparison with the EPR results is thus not possible. Of note is a large broadening of the $\mathrm{Ru}(\mathrm{CO})$ band of $[\mathrm{Zn} \text {-TPP-StyRu }]^{\bullet+}$ on cooling. Paralleling the increase of the IR band assigned to the $[\mathrm{Zn}$ TPP-StyRu $]^{0+}$ form, the broad electronic NIR transition also intensifies (SI Figure 16). This further supports the notion that both kinds of bands belong to the same species.

We assume that the extent of charge and spin (de)localization in $1^{\circ+}$ and $2^{\circ+}$ is triggered by conformational changes, i.e., rotation of the meso-styrylruthenium substituent with respect to the porphyrin or of the vinylruthenium moiety with respect to the styryl plane. IR spectra on samples of solid $\mathbf{1}^{\circ+}$, i.e., under conditions where rotation is blocked, only showed the $\mathrm{Ru}(\mathrm{CO})$ band of $\mathrm{Zn}$-TPP ${ }^{\circ+}$-StyRu from 0 to $50^{\circ} \mathrm{C}$ (SI Figure 18). Quantum chemical calculations were undertaken in order to investigate this point further. Structure optimization of neutral Zn-TPP-StyRu resulted in an interplanar angle of $63.2^{\circ}$ between the meso-styryl and the porphyrin planes (SI Figure 19). This is at the low end of values of similar meso-tetraarylporphyrins where interplanar angles are usually in the range of $65-88^{\circ}$. Even with this relative large deviation from coplanarity, the HOMO of the neutral complex and the unpaired spin density of its associated radical cation are fully delocalized over the porphyrin and the styrylruthenium moieties (SI Figures 20 and 21). Changes in the frontier orbital compositions of neutral 1 and spin density distributions in $1^{\circ+}$ as a function of the torsion around the porphyrin $\mathrm{C}_{\text {meso }}$-styryl $\mathrm{C}_{i p s o}$ and the styryl-vinyl bonds were mapped for torsional angles varying in $30^{\circ}$ steps between 0 and $360^{\circ}$. The softness of these degrees of freedom shown by our calculations demonstrates the accessibility of many different structures at finite temperature. No additional local minima could be identified with these rough scans. We note, however, that the unpaired spin becomes localized on the porphyrin ring if any of the two torsion angles adopts a value of $90^{\circ}$ (SI Figures 22 and 23). Reoptimization of these structures resulted in exactly the same delocalized structure as the first optimization. Due to limitations in the theoretical description of the system (approximations in the DFT functionals, no explicit solvents, neglect of finite temperature effects), no 
model for the structures with the more localized unpaired spin could be obtained.

In conclusion, radical cations $1^{\circ+}$ and $2^{\circ+}$, in $\mathrm{CH}_{2} \mathrm{Cl}_{2}$ solution, form a mixture of three thermally equilibrating, interconverting valence tautomeric species, two of which, $\mathbf{Z n -}$ TPP $^{\circ+}$-StyRu and $\mathrm{Zn}$-TPP-StyRu ${ }^{\circ+}$, have their charge and spin localized on one of the two different, yet nearly degenerate, redox sites while the third one displays extensive charge and spin delocalization over both. While $T$-dependent equilibria between two different MV VTs, ${ }^{11,12,13 a, 14}$ the simultaneous presence of localized and delocalized MV species, ${ }^{22}$ and conformation-controlled equilibria between MV end-group and bridge-oxidized redox isomers are known, ${ }^{15,23}$ we are not aware of another case where two different localized plus one additional delocalized VT MV species have been observed under the same conditions.

\section{ASSOCIATED CONTENT}

\section{Supporting Information}

Full experimental details and characterization data for $1-3$, and results of quantum chemical calculations on 1 , including supplemental Figures $1-23$ and Tables 1-4. This material is available free of charge via the Internet at http://pubs.acs.org.

\section{AUTHOR INFORMATION}

\section{Corresponding Author}

rainer.winter@uni-konstanz.de

Notes

The authors declare no competing financial interest.

\section{ACKNOWLEDGMENTS}

The authors gratefully acknowledge financial support of this work by the Deutsche Forschungsgemeinschaft (Wi1262/9-1). We also thank Malte Drescher and Martin Spitzbarth for helpful discussions and kind assistance with the simulation of the EPR spectra and Karin Hauser and Benjamin Heck for their assistance with the recording of variable- $T$ IR spectra on solid $1^{\circ+}$.

\section{REFERENCES}

(1) (a) Buchanan, R. M.; Pierpont, C. G. J. Am. Chem. Soc. 1980, 102, 4951. (b) Pierpont, C. G. Coord. Chem. Rev. 2001, 216-217, 99.

(2) (a) Evangelio, E.; Ruiz-Molina, D. C. R. Chimie 2008, 11, 1137. (b) Evangelio, E.; Ruiz-Molina, D. Eur. J. Inorg. Chem. 2005, 2957.

(3) (a) Sato, O.; Cui, A.; Matsuda, R.; Tao, J.; Hayami, S. Acc. Chem. Res. 2007, 40, 361. (b) Sato, O.; Tao, J.; Zhang, Y.-Z. Angew. Chem., Int. Ed. 2007, 46, 2152. (c) Wang, M.-S.; Xu, G.; Zhang, Z.-J.; Guo, G.C. Chem. Commun. 2010, 46, 361.

(4) Jørgensen, C. K. Coord. Chem. Rev. 1966, 1, 164.

(5) (a) Kaim, W. Inorg. Chem. 2011, 50, 9752. (b) Kaim, W. Eur. J. Inorg. Chem. 2012, 343.

(6) Pierpont, C. G.; Lange, C. W. Progress in Inorganic Chemistry; Karlin, K. D., Ed.; Wiley: New York, 1994; Vol. 41, p 331.

(7) Lever, A. B. P.; Masui, H.; Metcalfe, R. A.; Stufkens, D. J.; Dodsworth, E. S.; Auburn, P. R. Coord. Chem. Rev. 1993, 125, 317.

(8) Ward, M. D.; McCleverty, J. A. Dalton Trans. 2002, 275.

(9) Sproules, S.; Wieghardt, K. Coord. Chem. Rev. 2010, 254, 1358.

(10) (a) Dolphin, D.; Niem, T.; Felton, R. H.; Fujita, I. J. Am. Chem. Soc. 1975, 97, 5288. (b) Chang, D.; Malinski, T.; Ulman, A.; Kadish, K. M. Inorg. Chem. 1984, 23, 817. (c) Weiss, R.; Bulach, V.; Gold, A.; Terner, J.; Trautwein, A. X. J. Biol. Inorg. Chem. 2001, 6, 831.

(11) Ito, T.; Imai, N.; Yamaguchi, T.; Hamaguchi, T.; Londergan, C. H.; Kubiak, C. P. Angew. Chem., Int. Ed. 2004, 43, 1376.

(12) Salsman, J. C.; Kubiak, C. P. J. Am. Chem. Soc. 2005, 127, 2382.
(13) (a) Ratera, I.; Ruiz-Molina, D.; Renz, F.; Ensling, J.; Wurst, K. Rovira, C.; Gütlich, P.; Veciana, J. J. Am. Chem. Soc. 2003, 12S, 1462. (b) Ratera, I.; Sporer, C.; Ruiz-Molina, D.; Ventosa, N.; Baggermann, J.; Brouwer, A. M.; Rovira, C.; Veciana, J. J. Am. Chem. Soc. 2007, 129 6117

(14) (a) Kondo, M.; Uchikawa, M.; Namiki, K.; Zhang, W.-W. Kume, S.; Nishibori, E.; Suwa, H.; Aoyagi, S.; Sakata, M.; Murata, M.; Kobayashi, Y.; Nishihara, H. J. Am. Chem. Soc. 2009, 131, 12112 (b) Rao, K. P.; Kusamoto, T.; Toshimitsu, F.; Inayoshi, K.; Kume, S.; Sakamoto, R.; Nishihara, H. J. Am. Chem. Soc. 2010, 132, 12472. (c) Sakamoto, R; Rao, K. P.; Nishihara, H. Chem. Lett. 2011, 40, 1316. (15) (a) Lohan, M.; Justaud, F.; Lang, H.; Lapinte, C. Organometallics 2012, 31, 3565. (b) Lohan, M.; Justaud, F.; Roisnel, T.; Ecorchard, P.; Lang, H.; Lapinte, C. Organometallics 2010, 29, 4804.

(16) Maurer, J.; Linseis, M.; Sarkar, B.; Schwederski, B.; Niemeyer, M.; Kaim, W.; Záliš, S.; Anson, C.; Zabel, M.; Winter, R. F. J. Am. Chem. Soc. 2008, 130, 259.

(17) (a) Kowalski, K.; Linseis, M.; Winter, R. F.; Zabel, M.; Záliš, S.; Kelm, H.; Krüger, H.-J.; Sarkar, B.; Kaim, W. Organometallics 2009, 28, 4196. (b) Polit, W.; Exner, T.; Wuttke, E.; Winter, R. F. Bioinorg. React. Mech. 2012, 8, 85.

(18) Zeitouny, J.; Aurisicchio, C.; Bonifazi, D.; De Zorzi, R. Geremia, S.; Bonini, M.; Palma, C.-A.; Samori, P.; Listorti, A.; Belbakra, A.; Armaroli, N. J. Mater. Chem. 2009, 19, 4715.

(19) Fajer, J.; Borg, D. C.; Forman, A.; Dolphin, D.; Felton, R. H. J. Am. Chem. Soc. 1970, 92, 3451.

(20) Pevny, F.; Winter, R. F.; Sarkar, B.; Záliš, S. Dalton Trans. 2010, 8000

(21) Shimomura, E. T.; Phillippi, M. A.; Goff, H. M.; Scholz, W. F.; Reed, C. A. J. Am. Chem. Soc. 1981, 103, 6778.

(22) Hoekstra, R. M.; Telo, J. O. P.; Wu, Q.; Stephenson, R. M.; Nelsen, S. F.; Zink, J. I. J. Am. Chem. Soc. 2010, 132, 8825.

(23) (a) Fox, M. A.; Le Guennic, B.; Roberts, R. L.; Bruce, D. A.; Yufit, D. S.; Howard, J. A. K.; Manca, G.; Halet, J.-F.; Hartl, F.; Low, P. J. J. Am. Chem. Soc. 2011, 133, 18433. (b) Low, P. J. Coord. Chem. Rev. 2012, DOI: 10.1016/j.ccr.2012.08.008. (c) Costuas, K.; Cardor, O.; Le Stang, S.; Paul, F.; Monari, A.; Evangelisti, S.; Toupet, L.; Lapinte, P.; Halet, J.-F. Inorg. Chem. 2011, S0, 12601. 